\title{
Apropar els estudiants de Secundària al món de la Química
}

\author{
Imma Torra i M. Dolors Grau \\ Departament d'Enginyeria Minera i Recursos Naturals, Escola Politècnica Superior d'Enginyeria de Manre- \\ sa, Universitat Politècnica de Catalunya \\ torra@emrn.upc.edu; dolors@emrn.upc.edu
}

Es presenta l'experiència realitzada, durant diverses edicions, a l'Escola Politècnica Superior d'Enginyeria de Manresa (EPSEM) de la Universitat Politècnica de Catalunya (UPC), corresponent a dues activitats: L'exposició "On és la Química?" i el taller "Què és l'enginyeria química?" dirigides a estudiants de secundària.

\section{INTRODUCCIÓ}

L'objectiu de l'experiència és apropar els estudiants de secundària (ESO i Batxillerat) i Cicles Formatius al coneixement de la Química i despertar la seva curiositat pel món que ens envolta. La idea original pretenia mostrar que la Química es troba gairebé en tots els objectes que manipulem en la nostra vida diària. Per aquest motiu s'han dissenyat les dues activitats que es descriuen a continuació.

\section{CRITERIS METODOLÒGICS}

Els alumnes de batxillerat de les especialitats científica i tecnològica així com els que fan algun cicle formatiu de l'àmbit científic, són els més interessats en la Química i en les ciències en general. Tot i això, quan vàrem iniciar aquesta experiència vàrem tenir molt d'interès en dirigir-nos als estudiants de segon cicle de l'ESO ja que és on tenen el primer contacte amb la Química i, també, quan han de decidir quina especialitat de Batxillerat escolliran o bé si faran un cicle formatiu.

En la primera edició només vàrem organitzar l'exposició. En veure els resultats obtinguts en les enquestes passades als estudiants ens vàrem plantejar la necessitat d'incorporar uns tallers complementaris per permetre una major interactivitat dels estudiants.

Els temes que es proposen a l'exposició es poden adaptar molt bé al nivell de formació dels estudiants. Mentre que per als alumnes d'ESO es des- taquen propietats molt elementals, com la densitat, l'estat físic, la transparència... pels alumnes de Batxillerat o Cicles Formatius, s'aborden propietats més complexes com la facilitat d'oxidació, la solubilitat en aigua...

Els experiments que es fan en els tallers també es poden adaptar a l'edat dels estudiants. Els alumnes més joves fan destil-lacions i reaccions molt simples de forma qualitativa, mentre que els alumnes amb més coneixements poden fer destil-lacions més complexes i estudiar reaccions químiques de forma quantitativa.

\section{L’EXPOSICIÓ “ON ÉS LA QUÍMICA?”}

L'exposició s'ha estructurat en tres apartats diferents de manera que els estudiants poden fer diverses activitats, en algunes de les quals hi tenen una participació molt activa.

\subsection{Projecció de l‘audiovisual "La Química i nosaltres"}

Aquest audiovisual mostra com la Química és en tots els materials que manipulem en la mostra vida diària (FeiQue, 2001). Es pot comprovar que des que ens llevem constantment estem utilitzant productes elaborats amb la participació de la Química. L'objectiu és que els estudiants apreciïn la importància de la Química a les nostres vides. (Durada: 30 min.) 


\subsection{Visita a l'exposició}

Aquí es fa pròpiament la visita a l'exposició que, de nou, consta de tres apartats. (Durada: $30 \mathrm{~min}$.)

\subsubsection{Taula periòdica: dels elements al producte acabat}

A partir d'una Taula Periòdica gegant on cada element es presenta de forma visual amb l'aspecte que té a la realitat (www.webelements.com), s'aprofundeix en el coneixement de 15 elements concrets: $\mathrm{K}, \mathrm{Mg}, \mathrm{Ca}, \mathrm{Ba}, \mathrm{Mn}, \mathrm{Fe}, \mathrm{Cu}, \mathrm{Hg}, \mathrm{Al}, \mathrm{C}, \mathrm{Si}, \mathrm{Pb}, \mathrm{S}, \mathrm{F}$, $\mathrm{Na}$. De cadascun se n'indiquen les propietats més característiques (Chang 1999). Cada element s'acompanya (fig. 1) d'una mostra del mineral a partir del qual s'obté i de diferents estris quotidians on s'hi troba l'element.

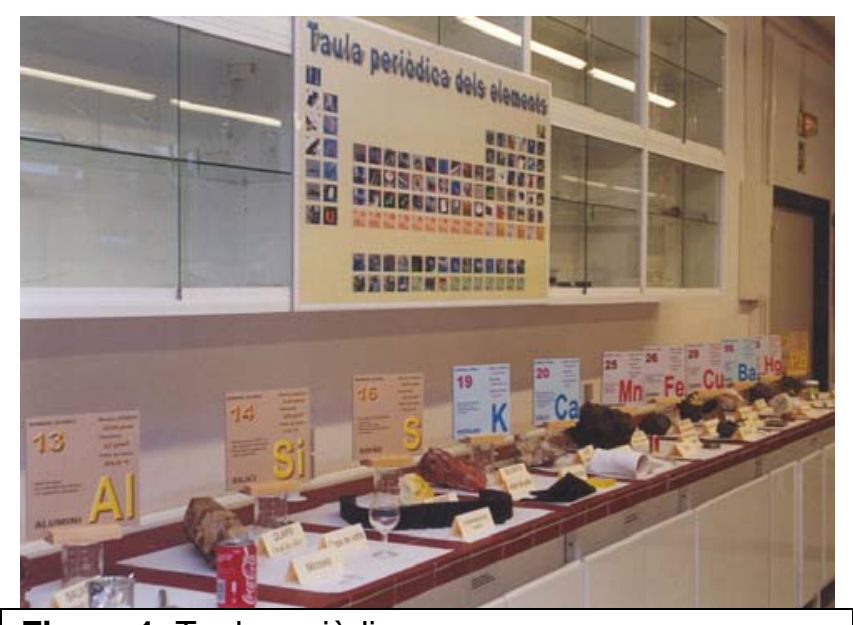

Figura 1. Taula periòdica

\subsection{2. ¿On és la Química?}

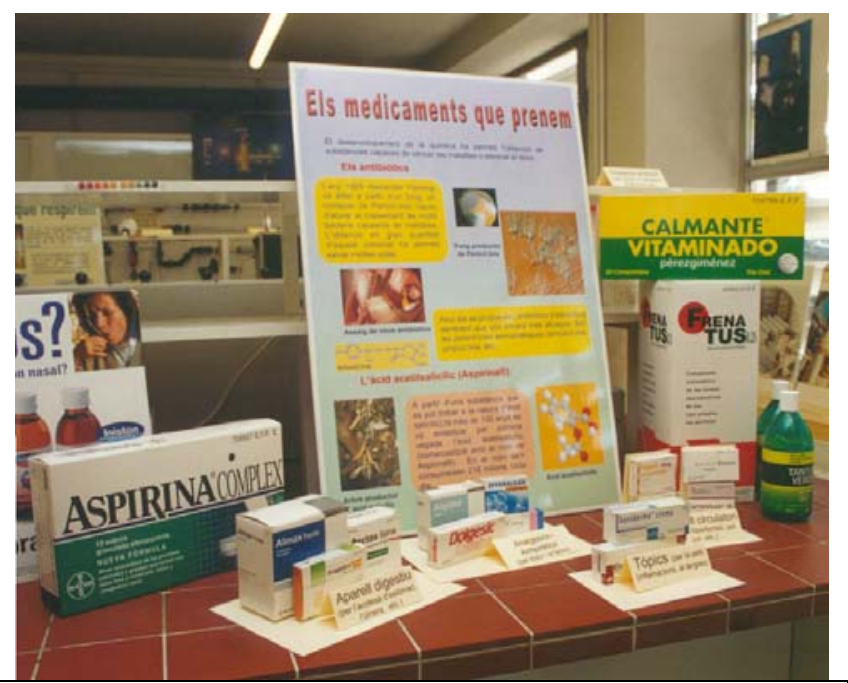

Figura 2. Els medicaments que prenem
Conjunt d'onze pòsters de diferents àmbits on es troba la Química, tots ells imprescindibles per a la nostra vida i subsistència diària: "L'aire que respirem", "L'aigua que bevem", "Els aliments que mengem", "Els medicaments que prenem" (fig. 2), "Els detergents que utilitzem", "Els camps que adobem", "La casa que habitem", "La roba que vestim", "Els combustibles que consumim", "Les deixalles que reciclem" (fig. 3), "Els cotxes que conduïm".

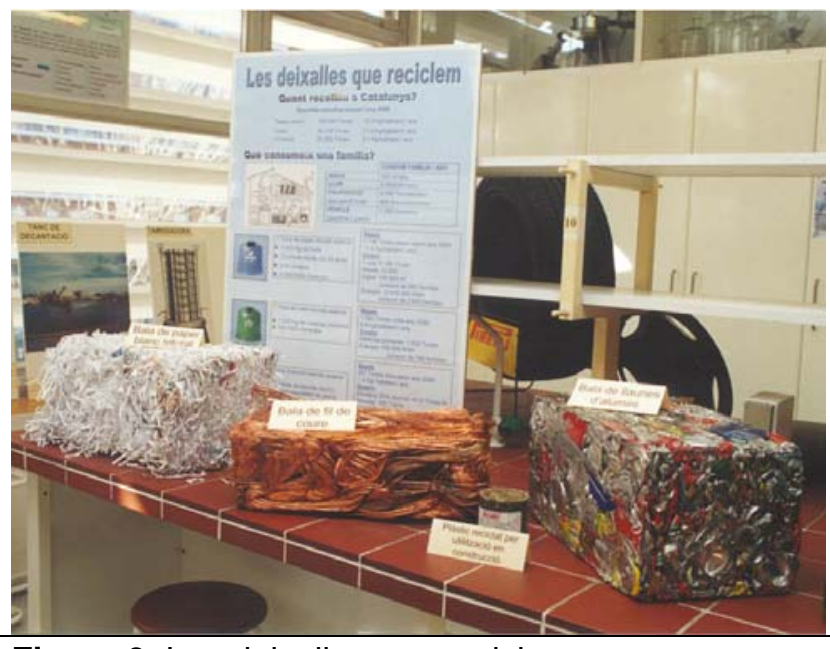

Figura 3. Les deixalles que reciclem

Els pòsters van acompanyats de material relacionat amb els continguts mostrats i que els estudiants poden manipular.

\subsubsection{La planta química industrial}

Aquest apartat tanca l'exposició i mostra com s'obtenen els diferents productes que s'han presentat en els apartats anteriors. D'aquesta tasca se n'encarrega la indústria química en "La Planta Química Industrial". Es presenten diferents fotografies (en format pòster) dels equips habituals en una planta química (operacions físiques i químiques), acompanyades de les explicacions corresponents (Vian Ortuño, 1998).

\subsection{Treballs a Internet}

Aquí els estudiants han de respondre un qüestionari relacionat amb la temàtica de l'exposició mitjançant la consulta a diverses pàgines Web que se'ls faciliten. (Durada $30 \mathrm{~min}$ )

\section{EL TALLER “QUÈ ÉS L'ENGINYERIA QUÍMICA?"}

A partir dels suggeriments dels professors i dels estudiants que van visitar l'exposició, en la segona 
edició hi vàrem incorporar una nova activitat destinada fonamentalment a mostrar com intervé la Química per a produir tots els productes que usem quotidianament, sense els quals no podríem disposar de la qualitat de vida actual. De fet es tracta de l'ampliació del darrer apartat de l'exposició dedicat a la Planta Química Industrial. Els tallers presenten als estudiants l'escala de treball a nivell industrial a través dels pòsters, l'escala de treball amb plantes pilot i l'escala de treball al laboratori on ells realitzen les experiències. L'activitat té una durada de dues hores.

A la primera part del taller es mostra el funcionament bàsic de cinc plantes pilot que habitualment usen els nostres estudiants per fer les pràctiques de la titulació d'Enginyeria Tècnica Industrial en l'especialitat de Química Industrial (fig. 4 i 5):

- Transport de fluids

- Intercambiador de calor

- Maqueta de control

- Reactor químic

- Columna de destil.lació

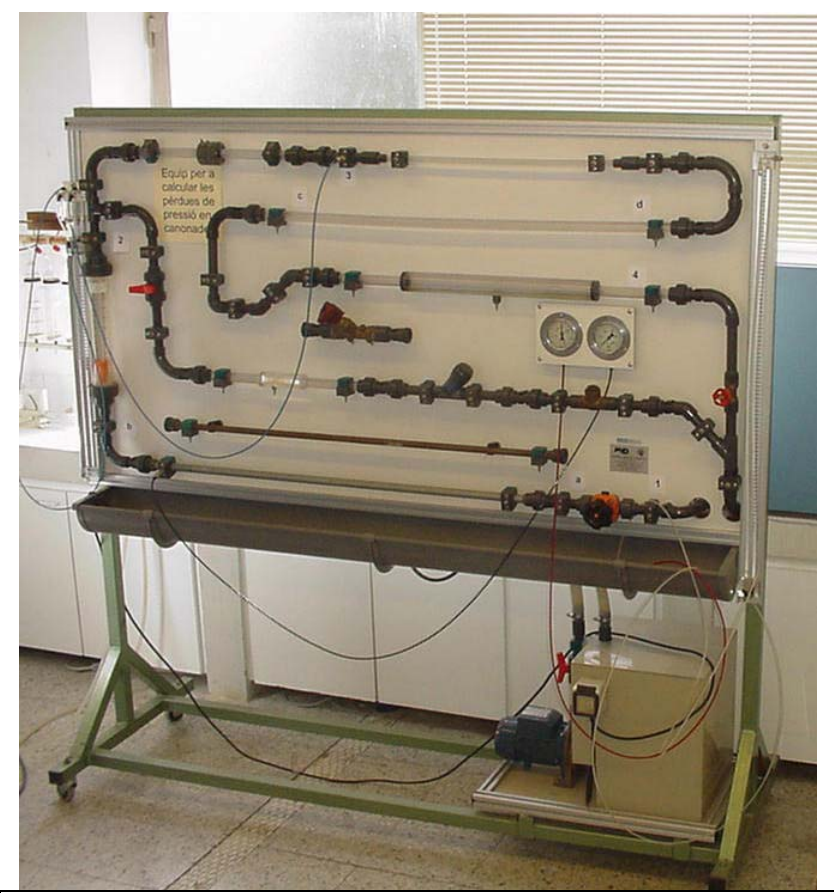

Figura 4. Transport de fluids.

Les explicacions s'adapten al nivell de coneixements dels estudiants ja que es pot treballar en diferents graus d'aprofundiment segons si els estudiants són d'ESO, de Batxillerat o d'algun cicle formatiu relacionat amb la Química. Els estudiants poden fer alguna mesura experimental sobre aquestes plantes, sempre de forma controlada pel professor.

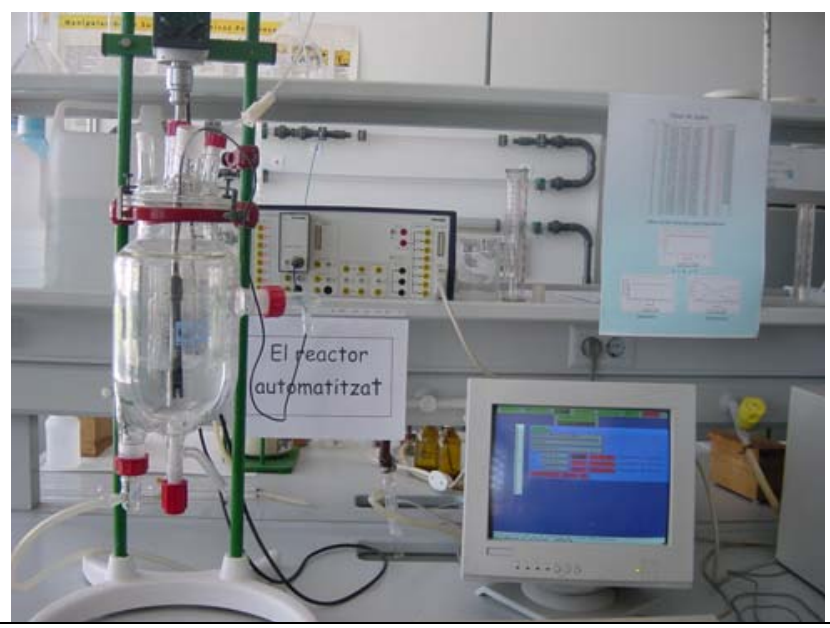

Fig. 5. Reactor químic.

A la segona part els estudiants fan activitats pràctiques en grups de dos, reproduint les mateixes operacions anteriors a escala de laboratori. Les pràctiques que es proposen són senzilles i consisteixen bàsicament en destil-lacions i reaccions químiques seleccionades per mostrar els mateixos processos que porta a terme la indústria química a gran escala. Disposem de pràctiques amb diferents nivells per adaptar-les al grau de coneixement dels alumnes del grup.

Després d'aquesta activitat els alumnes poden tenir clares les tres escales de treball: la industrial, la de les plantes pilot i la del laboratori que, sovint, és la que els resulta més familiar.

\section{VALORACIÓ DE L'EXPERIĖNCIA}

Com que l'experiència consta de dos apartats ben diferenciats (l'exposició i els tallers), analitzarem per separat les seves característiques i els resultats obtinguts en la valoració que n'han fet els alumnes.

\subsection{Valoració de l'Exposició}

El curs passat van visitar l'exposició 681 alumnes dels quals vàrem recollir 510 enquestes. (Cal dir que 145 d'aquests estudiants varen fer també els tallers). L'enquesta que van contestar contenia com a pregunta clau si consideraven que la visita havia valgut la pena, i els resultats van ser:

- Dels alumnes que només han visitat l'exposició un 48,3\% respon "Molt Bé", i un 49,6\% respon "Bé" (fig. 6).

- Dels 145 alumnes que quan han vingut a la nostra Escola a més de veure l'exposició han fet els tallers, un 41,4\% respon "Molt Bé" i un 57,9\% respon "Bé" (fig.7). 
¿La visita ha valgut la pena?

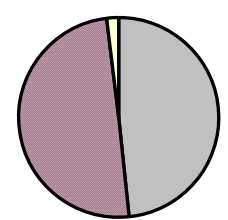

$\square$ Molt Bé

口Bé

$\square$ Malament

Figura 6. Respostes dels alumnes que només han visitat l'exposició.

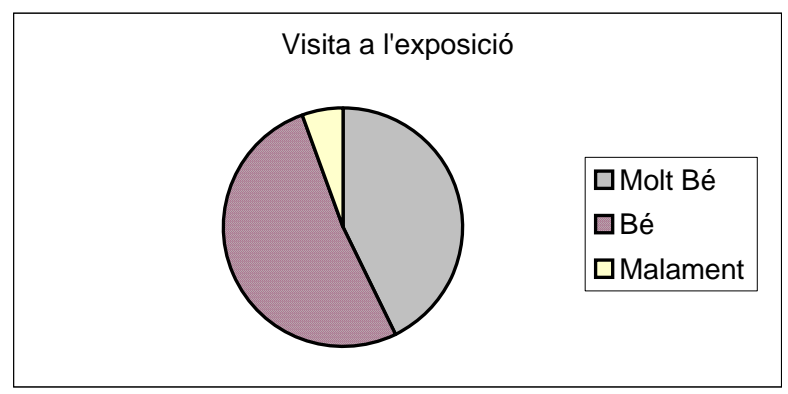

Figura 7. Respostes dels alumnes que han visitat l'exposició i han fet els tallers.

Una anàlisi més detallada dels resultats ens indica que quan els alumnes fan les dues activitats de forma consecutiva, la visita a l'exposició els resulta menys atractiva ja que augmenta el percentatge d'alumnes que la valoren com "Bé" mentre disminueix el percentatge d'alumnes que en fan una valoració de "Molt Bé". Cal destacar però, que el conjunt de les dues valoracions dóna aproximadament el mateix resultat.

A la taula 1 es mostra una anàlisi més detallada, amb les respostes a totes les preguntes sobre l'exposició, pels alumnes que han fet les dues activitats.

\begin{tabular}{|c|c|c|c|}
\hline $\begin{array}{l}\text { "On és la } \\
\text { Química?" }\end{array}$ & Molt bé & Bé & Malament \\
\hline Audiovisual & 39 & 105 & 1 \\
\hline Visita a l'exposició & 62 & 75 & 8 \\
\hline Treballs a internet & 40 & 98 & 7 \\
\hline $\begin{array}{l}\text { La visita ha valgut la } \\
\text { pena? }\end{array}$ & 60 & 84 & 1 \\
\hline
\end{tabular}

Taula 1. Resultats de les enquestes sobre l'exposició.

\subsection{Valoració dels tallers}

En aquest cas els estudiants que han fet els tallers són 277, dels quals 145 també han visitat l'exposició, tal com s'ha indicat a l'apartat anterior. A tots els estudiants se'ls va passar una enquesta sobre diferents aspectes de l'experiència però aquí destacarem només la resposta a la pregunta més global: si l'activitat ha valgut la pena. Els resultats són:

- Dels 132 alumnes que només van fer els tallers, un $50,7 \%$ contesta "Molt Bé" i un 47,7\% contesta "Bé" (fig. 8).

- Dels 145 alumnes que a més dels tallers van visitar l'exposició, un 58,6\% contesta "Molt Bé" i un 39,3\% contesta "Bé" (fig. 9).

En aquest cas podem constatar que el percentatge d'alumnes que contesten "Bé" o "Molt Bé" no varia massa en els dos grups estudiats.

Entre aquest resultat i el de l'apartat anterior, posem deduir que quan els alumnes realitzen els tallers, la sessió els resulta més atractiva.

\section{¿La visita ha valgut la pena?}

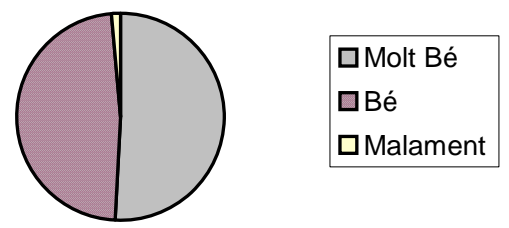

Figura 8. Respostes dels alumnes que només han fet els tallers.

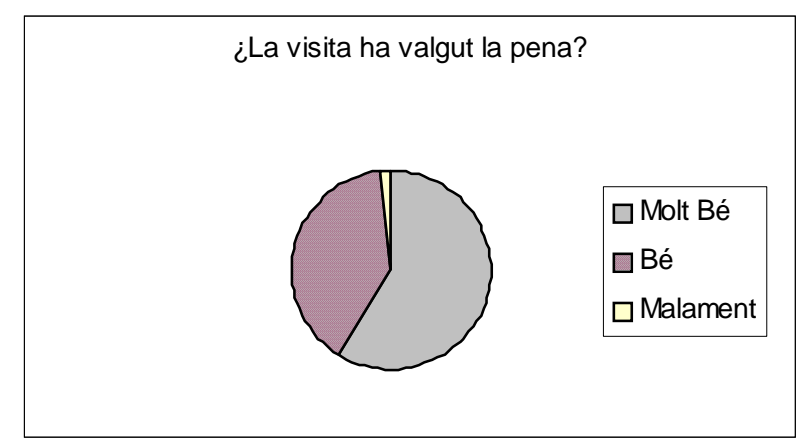

Figura 9. Respostes dels alumnes que han fet els tallers, a més de la visita a la exposició.

A la Taula 2 es fa una anàlisi més detallada amb les respostes a totes les preguntes fetes sobre els tallers, pels alumnes que han fet les dues experiències. 


\begin{tabular}{|c|c|c|c|}
\hline $\begin{array}{l}\text { "Què és } \\
\text { l'enginyeria química?" }\end{array}$ & Molt bé & Bé & Malament \\
\hline $\begin{array}{l}\text { Explicació enginyeria } \\
\text { química }\end{array}$ & 50 & 82 & 13 \\
\hline $\begin{array}{l}\text { Experiments de labora- } \\
\text { tori }\end{array}$ & 113 & 29 & 3 \\
\hline $\begin{array}{l}\text { La visita ha valgut la } \\
\text { pena? }\end{array}$ & 85 & 57 & 3 \\
\hline
\end{tabular}

Taula 2. Resultats de les enquestes sobre els tallers.

Vegem ara quina és la valoració que fan els estudiants sobre les experiències de laboratori (separant la part de l'explicació que fa el professor sobre les plantes pilot). Aquí seguim utilitzant els dos grups d'anàlisi:

- Dels alumnes que només han fet els tallers un $66,7 \%$ contesta "Molt Bé" i un 31,1\% "Bé" (fig. 10).

- Dels alumnes que a més de fer els tallers han visitat l'exposició, un 77,9\% contesta "Molt Bé" i un $20,0 \%$ contesta "Bé" (fig. 11).

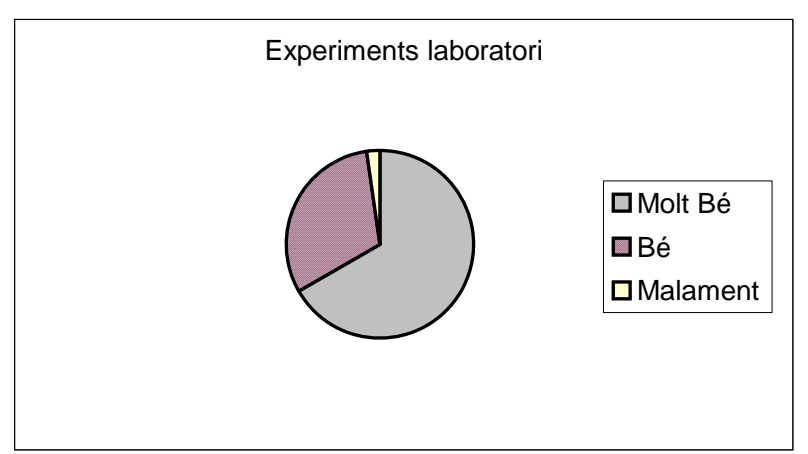

Figura 10. Respostes dels alumnes que només han fet els tallers.

Podem constatar que la quantitat d'alumnes que responen "Bé" o "Molt Bé" a la realització de les experiències és molt alta. Aquesta dada és molt positiva per a nosaltres ja que ens indica que tot l'esforç realitzat en el disseny i el muntatge de les activitats resulta molt ben valorat pels estudiants.

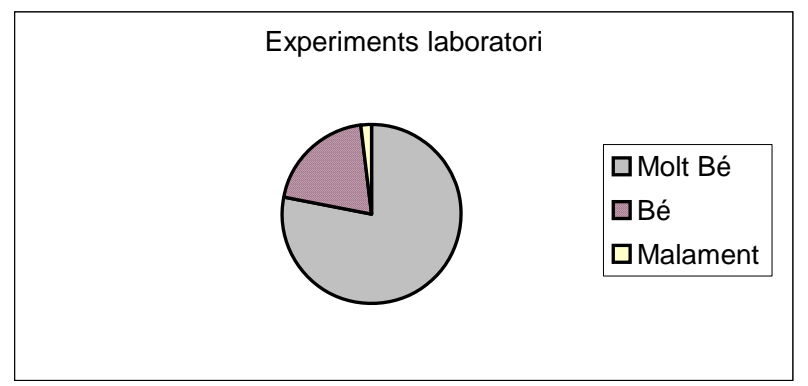

Figura 11. Respostes dels alumnes que han fet els tallers, a més de la visita a l'exposició.

\section{CONCLUSIONS}

L'experiència ha resultat ser molt positiva en tots els aspectes. Per part del professorat de secundària ha tingut molt bona acollida, ja que no tenim coneixement d'altres activitats d'aquest tipus per estudiants d'aquest nivell. D'altra banda el professorat valora el fet que els estudiants puguin tenir una visió molt propera de la química, així com el fet de poder realiltzar pràctiques de laboratori. I per part dels alumnes les enquestes ens mostren un bon grau de satisfacció.

Malgrat tot, cal tenir en compte l'elevat esforç que ha representat aquesta experiència per al professorat de la universitat ja que a més de la preparació del material, com que es treballa amb grups molt reduïts (de 15 alumnes com a màxim), requereix un temps molt important de dedicació.

Els resultats de les enquestes són molt bons però ens indiquen que estudiants de $3 \mathrm{r}$ i $4 \mathrm{t}$ d'ESO que fan les dues activitats de forma consecutiva, ho troben massa dens. Potser seria aconsellable programar les dues experiències en dies diferents.

\section{PER A MÉS INFORMACIÓ}

\author{
Escola Politècnica Superior d'Enginyeria \\ de Manresa \\ Avda. de les Bases de Manresa, 61-73 \\ 08242 Manresa \\ Tel: 938777228 \\ www.epsem.upc.edu/expoquimica
}

\section{REFERÈNCIES}

FeiQue (2001). La Química y nosotros. Madrid.

CHANG, R. (1999). Química. New York: McGrawHill.

VIAN ORTUÑO, A. (1998). Introducción a la Química Industrial. Madrid: Alhambra. 